\title{
PROPRIEDADE INTELECTUAL NO CENÁRIO INTERNACIONAL: ORGANISMOS DE PROTEÇÃO E O ACORDO TRIPS
}

\author{
Florisbal de Souza Del'Olmo ${ }^{1}$ \\ Olivério de Vargas Rosado ${ }^{2}$ \\ Thiago Luiz Rigon de Araujo ${ }^{3}$
}

\begin{abstract}
RESUMO
O presente artigo tem por escopo estudar a questão da Propriedade Intelectual no cenário internacional, fazendo uma abordagem do histórico desse instituto jurídico e seus desdobramentos, sendo no estudo dos tratados internacionais e na criação dos organismos internacionais que visam dar guarida a esses direitos. A criação da OMPI (Organização Mundial da Propriedade Intelectual) foi um grande avanço, pois além de ser um órgão das Nações Unidas especializado na matéria, teve em seu principal objetivo disciplinar e proteger os direitos intelectuais. Consequentemente, com a dinamização do comércio em escala mundial e a intensificação das relações internacionais de cunho comercial, uma otimização dos órgãos competentes se fez necessária, haja vista a criação da OMC (Organização Mundial do Comérico) em substituição do já ultrapassado GATT ( Acordo Geral de Tarifas e Comércio). Nesse sentido, também fora necessário a criação de um novo documento internacional sobre a propriedade intelectual, surge então o TRIPS (Trade Related Aspects of Intellectual Property Rights), tendo como seus propósitos centrais a redução de distorções e obstáculos ao comércio internacional e assegurar o cumprimento das medidas e procedimentos de proteção a propriedade intelectual, e, inclusive o ter o propósito de amenizar as tenções entre os países ricos detentores das pesquisas no campo da biodiversidade e os países pobres detentores da biodiversidade.
\end{abstract}

PALAVRAS-CHAVE: PROPRIEDADE INTELECTUAL; OMPI; TRIPS; BIODIVERSIDADE.

\section{INTRODUÇÃO}

Propriedade intelectual é um monopólio concedido pelo estado. Segundo a Convenção da OMPI, é a soma dos direitos relativos às obras literárias, artísticas e científicas, às interpretações dos artistas intérpretes e às execuções dos artistas executantes, aos fonogramas e às emissões de radiodifusão, às invenções em todos os domínios da atividade humana, às descobertas científicas, aos desenhos e modelos industriais, às marcas industriais, comerciais e de serviço, bem como às firmas

\footnotetext{
${ }^{1}$ Mestre pela Universidade Federal de Santa Catarina (UFSC), Doutor em Direito pela Universidade Federal do Rio Grande do Sul (UFRGS) e Pós-Doutor em Direito (UFSC). Professor Programa de PósGraduação em Direito, pela Universidade Regional Integrada do Alto Uruguai e das Missões (URI), Santo Ângelo -RS

2 Mestrando do Programa de Pós-Graduação em Direito, pela Universidade Regional Integrada do Alto Uruguai e das Missões (URI). Professor da URI Frederico Westphalen. E-mail oliveriorosado@yahoo.com.br

${ }^{3}$ Mestrando do Programa de Pós-Graduação em Direito, pela Universidade Regional Integrada do Alto Uruguai e das Missões (URI). Membro integrante do Grupo de Pesquisa em Direito da Sociobiodiversidade da Universidade Federal de Santa Maria. E-mail: rigondearaujo@gmail.com
} 
comerciais e denominações comerciais, à proteção contra a concorrência desleal e todos os outros direitos inerentes à atividade intelectual nos domínios industrial, científico, literário e artístico.

Historicamente, a preocupação com a tutela dos direitos de autores de obras intelectuais é bastante recente. Na Antiguidade e na maior parte da Idade Média as dificuldades inerentes aos processo de reprodução dos originais, por si só, já exerciam um poderoso controle da divulgação de ideias, pois o número de cópias de cada obra era naturalmente limitado pelo trabalho manual dos copistas.

Com a invenção da imprensa, os soberanos sentiam-se ameaçados com a iminente democratização da informação e criaram um ardiloso instrumento de censura, consistente em conceder aos donos dos meios de produção dos livros o monopólio da comercialização dos títulos que editassem, a fim de que estes, em contrapartida, velassem para que o conteúdo não fosse desfavorável à ordem vigente.

Em 1557, dezoito anos depois que Wiliam Caxton introduziu na Inglaterra a máquina de escrever (printing press), Filipe e Maria Tudor concederam à associação de donos de papelaria e livreiros o monopólio real para garantir-lhes a comercialização de escritos. A corporação, então, tornou-se uma valiosa aliada do governo em sua campanha para controlar a produção impressa. Eram comerciantes que, em troca da proteção governamental ao seu domínio de mercado, manipulavam os direitos do indivíduo ao conteúdo, exercendo a censura sobre aqueles que lhe fossem desfavoráveis na oposição à realeza.

A esse privilégio no controle dos escritos chamou-se copyright, que nasceu, pois, de um direito assegurado aos livreiros, e não como um direito do autor dos escritos. Durou mais ou menos duzentos anos, e é a semente das leis (Statutes) relativas a esse direito herdadas pela Inglaterra, e, mais tarde, pelos Estados Unidos da América do Norte.

A primeira lei inglesa, de 1710, dava ao criador o direito exclusivo sobre um livro por 14 anos e, se o autor ainda estivesse vivo quando o direito expirasse, poderia renovar o direito por mais 14 anos. A legislação americana baseou-se na inglesa e nos atos de patentes e de direitos autorais de 1790 retomou os períodos de 14 anos, renováveis por outros 14. Em 1831, o Congresso americano revisou as leis de direitos autorais substituindo o período inicial de 14 anos, por um de 28, renovável por mais 14 . 
Em 1909, as leis foram novamente revisadas e o período foi mais uma vez ampliado para 28 anos iniciais renováveis por mais 28 anos.

Mais recentemente, porém, com o aumento do poder da indústria cultural, a extensão do direito à propriedade intelectual ultrapassou de longe os vinte anos após a morte que incomodavam o historiador Thomas Macaulay em 1841. As pressões começaram em 1955, quando o Congresso americano autorizou o escritório de patentes a desenvolver um estudo com vistas a revisar as leis de direito autoral vigentes. $\mathrm{O}$ relatório final recomendava a ampliação do período de renovação de 28 para 48 anos.

As organizações de escritores e a indústria cultural (principalmente as editoras), no entanto, insistiam num período que cobrisse a vida do autor mais 50 anos após a sua morte. O pretexto para esse período longuíssimo era a "modernização" das leis de direitos autorais e a adequação delas à Convenção de Berna. Como a disputa não parecia poder ser resolvida no curto prazo e os direitos estavam começando a expirar, os lobistas conseguiram um adiamento extraordinário do vencimento dos direitos que estavam por expirar, do ano de 1962 para o ano de 1965, enquanto a matéria não era definitivamente votada no Congresso.

Apesar das reiteradas objeções do Departamento de Justiça, a polêmica em torno do assunto levou a outros oito adiamentos "extraordinários", de 1965 para 1967, de 1967 para 1968, de 1968 para 1969, de 1969 para 1970, de 1970 para 1971, de 1971 para 1972, de 1972 para 1974 e de 1974 para 1976, tudo em nome dos interesses dos detentores dos direitos (normalmente empresas e não os descendentes dos autores) e em detrimento do domínio público. Em 1976, finalmente, o Congresso aprovou uma nova e "moderna" lei de direitos autorais, atribuindo um período de vigência do direito por toda a vida do autor mais 50 anos e para trabalhos encomendados por empresas, um período de 75 anos após a publicação ou 100 anos após a criação, o que fosse mais curto.

Em 20 de março de 1883, vários países se reuniram para firmar um tratado que assegurasse a propriedade intelectual de forma relativamente uniforme ao redor do mundo, mas garantindo relativa liberdade aos seus signatários. O resultado disso foi o tratado da Convenção de Paris para a Proteção da Propriedade Industrial.

O tratado sofreu várias revisões desde então: em Bruxelas a 14 de dezembro de 1900; em Washington a 2 de junho de 1911; em Haia a 6 de novembro de 1925; em 
Convenção de Estocolmo, tem por escopo a proteção e normatização da propriedade intelectual. Sediado em Genebra, esse organismo especializado da ONU, foi oriundo da Convenção da União de Paris para a Proteção da Propriedade Industrial celebrada em 1883, bem como Convenção de Berna para a proteção das Obras Literárias e Artísticas compactuada em 1886, ambas marcos da criação das convenções jurídicas internacionais.

É importante ressaltar, que embora esses tratados tenham sido celebrados no século XIX, seus textos são de grande relevância, como nos trás a baila a sábia lição de Salete Oro Boff:

\begin{abstract}
"Os seus textos preveem a regulamentação dos conflitos de leis e de jurisdição; da condição dos estrangeiros e o gozo dos seus direitos; o proncípio do tratamento unionista. De igual forma, traduz-se em limite a faculdade de os Estados regularem, de maneira independente, uma matéria de extrema importância e de caráter internacional.(BOFF, 2006, p.258)
\end{abstract}

Outrossim, pode-se denotar que dentre as finalidades estabelecidas pela OMPI previstas no art. $3^{\circ}$ da Convenção de Estocolmo, estão sintetizadas das seguintes formas: promover a proteção da Propriedade Intelectual em todos os países, desde que haja uma cooperação desses Estados, e, inclusive a cooperação de quaisquer organizações internacionais, sempre no âmago de garantir uma cooperação na esfera administrativa entre as demais entidades que se correlacionam no tema da Propriedade Intelectual.

A OMPI tem como medidas centrais, no sentido de sua funcionalidade, otimizar a proteção da Propriedade Intelectual em escala mundial, harmonizar as leis dos países, difundir e divulgar informações e estudos sobre a matéria, incentivar a instituição de acordos internacionais, dar assistência técnica e também jurídica, bem como a estimulação e promoção de medidas para a atividade intelectual criadora e facilitar a transmissão de tecnologia para os países em desenvolvimento.(BOFF, 2006, p.255)

Entretanto, devido a mudanças de estratégias dos países ricos, já no âmbito da OMC, os quais representam os proprietários dos detentores dos direitos de Propriedade Intelectual o que na visão de Roberto Castelo Branco Coelho de Souza (2007, p.1), os referidos países vislumbram a oportunidade de modificar os tratados administrados pelo OMPI, e, "de obter concessões que acrescentariam vantagem comerciais ao modificar questões que na superfície seriam formalidades administrativas ou qustões de natureza 




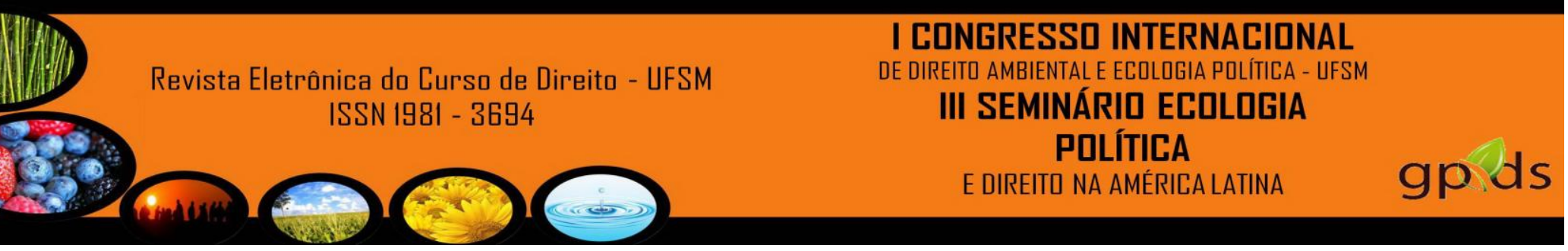

No entanto, afora os aspectos aludidos supra, com estudo dos organismos internacionais mostrou-se possível a reflexão que nem sempre os interesses dos países subdesenvolvidos, os quais detém uma enorme biodiversidade são atendidos pelas organizações especializadas no tema, o que vem a calhar em uma criação de tensão nas relações destes países com os países desenvolvidos, onde se oriunda as grandes empresas transnacionais que possuem grandes investimentos em andamento.

Igualmente, é possível afirmar que mesmo com a criação do TRIPS, que tem uma relevância destacada na presente questão, seja para uma uniformização e padronização da propriedade intelectual seja na sua proteção em âmbito internacional, o mostrando também a necessidade de maiores estudos em busca de uma aperfeiçoamento desse tema, o que desde já mostra-se justificado o presente estudo.

Por fim, podemos concluir que as normas que visam a integração e uniformização da Propriedade Intelectual, bem como os conflitos existentes nos ordenamentos jurídicos dos países, mostram-se que ainda possuem um pretenso caminho a percorrer, afim de que possam contribuir na amenização das tensões existentes entre países, evitando a ocorrência de injustiças aos povos que detém o conhecimento tradicional sobre a biodiversidade.

\section{REFERÊNCIAS}

BASSO, Maristela. Os fundamentos atuais do Direito Internacional da Propriedade Intelectual. In: $C E J$, Brasília, n.21, abr/jun. p.16-30

BOFF, Salete Oro. Patentes na Biotecnologia e desenvolvimento. In: BARRAL, Welber e PIMENTEL, Luiz Otávio(orgs). Propriedade Intelectual e Desenvolvimento. Florianópolis: Fundação Boitex, 2006, pp. 253-279.

DEL NERO, Patrícia Aurélia. Propriedade intelectual: a tutela jurídica da biotecnologia. São Paulo: Editora Revista dos Tribunais, 2004.

DEL'OLMO, Florisbal de Souza; MELEU, Marcelino; SILVERA, Joceli Antônio Mossati. A Proteção da Propriedade Intelectual no Âmbito Internacional e suas Relações com o Direito Privado. In: BOFF, Salete Oro; DEL'OLMO, Florisbal de Souza; PIMENTEL, Luiz Otávio; Propriedade Intelectual: Gestão do conhecimento, inovação tecnológico no agronegócio e cidadania. Florianópolis: Fundação Boitex, 2008. 242p. 


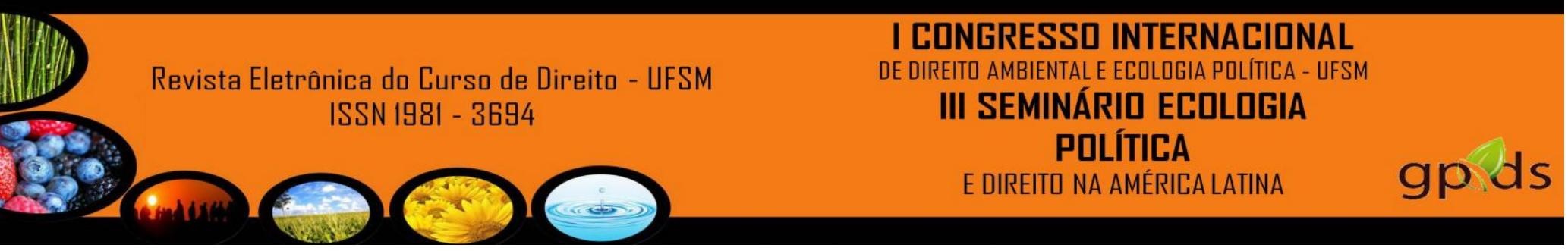

PIMENTEL, Luiz Otávio; DEL NERO, Patrícia Aurélia. A OMC, a Propriedade Intelectual e a Biotecnologia. In: DEL'OLMO, Florisbal de Souza (coord.). Curso de Direito Internacional Contemporâneo. São Paulo: Forense. 2003. PP.443-465

SOUZA, Roberto Castelo Branco Coelho de. TRIPS na Organização Mundial da Propriedade Intelectual -OMPI. Disponível em http://www.eco.unicamp.br/aspscripts/boletim_ceri/boletim/boletim5/05_Castelo Branco.pdf Acesso em Agosto 2012. In: PIMENTEL, Luiz Otávio; BOFF, Salete Oro; DEL'OLMO, Florisbal de Souza. Propriedade Intelectual: Gestão do conhecimento, inovação tecnológico no agronegócio e cidadania. Florianópolis: Fundação Boitex, 2008. 242p.

VARELLA, Marcelo Dias. Direito Internacional Econômico Ambiental. Belo Horizonte: Del Rey, 2003. 